\title{
Management of pharmaceutical waste in hospitals in Serbia - challenges and the potential for improvement
}

\author{
Verica Jovanović ${ }^{1}$, Jelena Manojlović ${ }^{2}$, Dragomir Jovanović ${ }^{3}$, Branislava Matic ${ }^{1}$, Nela Đonović ${ }^{4}$ \\ 'Institute of Public Health of Serbia "Dr Milan Jovanovic Batut", Belgrade, Serbia. \\ 'University of Belgrade Faculty of Pharmacy, Belgrade, Serbia. \\ ${ }^{3}$ Clinic for Gynecology and Obstetrics, GAK "Narodni front", Belgrade, Serbia. \\ ${ }^{4}$ University of Kragujevac, Medical Faculty, Kragujevac, Serbia.
}

\begin{abstract}
Background: Left over medication widely used in hospitals for the treatment of various diseases including malignant illnesses, stand to represent a hazardous form of healthcare waste. According to regulations in the Republic of Serbia dating back to 2009, all healthcare facilities are obligated to separate, label and safely put away said leftover medication, i.e. forward it to authorised operators in order to be securely shipped and properly taken care of abroad. Pharmaceutical waste can lead to dire consequences on a patient's or medical employee's health, as well as cause simultaneous damage to the environment, both work and not. The main aim of this research is the assessment of the state of Serbian hospitals as is, from the perspective of dealing with pharmaceutical waste. Also, the research's objective is to examine the factors that affect the way healthcare waste is handled and the respectful aftermath of their alterations in healthcare institutions. Methods: For the realization of this survey, a special questionnaire was developed, concocted with regard to the margins set out by WHO, in order to promptly assess the management of healthcare waste in hospitals, which had beforehand been pretested. The research was carried out as a cross-sectional study of the representative hospital sample of the secondary and tertiary level of healthcare facilities in the public domain, in November 2014. Results: The questionnaire was completed by 60 hospitals, which typifies a representative number of said facilities in the Republic of Serbia and which covers more than $85 \%$ of inpatient capacity within the public sector's network of healthcare hospitals defined by the Bylaw (referred to as the Network of healthcare facilities in Serbia). Conclusion: Tertiary level hospitals, meaning clinical centres, clinicalmedical centres and institutes that offer highly specialized healthcare services and have an admittedly larger number of hospital beds, have a more evolved system of sorting pharmaceutical waste and do away with grander amounts of it on a yearly basis. Establishing a safe and law-abiding management of pharmaceutical waste in hospitals will come to wholly enhance the management of hazardous waste in the healthcare system.
\end{abstract}

Key words: Healthcare waste management, factors, pharmaceutical waste, training, hospital
Submission Date : 01-06-2016

Revision Date : 19-07-2016

Accepted Date : 10-08-2016

DOI: 10.5530/ijper.50.4.22

Correspondence:

*Verica Jovanovic

Institute of Public Health of

Serbia "Dr Milan Jovanović

Batut", Centre for Diseases

Control, Dr Subotica 5,

11000 Belgrade, Serbia

$+381112062733$

+381637626 631

E-mail:verica_jovanovic@

batut.org.rs

\section{INTRODUCTION}

The term healthcare waste includes all waste generated within healthcare facilities, research centres and laboratories related to the provision of medical services. According to respectful literature, between $75 \%$ and
$90 \%$ of the waste produced by healthcare providers is comparable to domestic waste and usually referred to as "non-hazardous" or "general healthcare waste". The remaining $10-25 \%$ of healthcare waste is regarded as

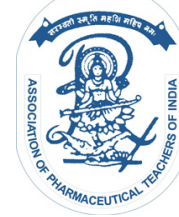

www.ijper.org 
"hazardous" and may involve a variety of environmental and health risks. ${ }^{1}$ Pharmaceutical waste is a category of healthcare waste that belongs to the hazardous healthcare waste stream. The major sources of such healthcare waste are hospitals. Hospitals generate daily pharmaceutical and cytostatic waste during the provision of healthcare services to patients. One of the important overall objectives of every healthcare facility should be the implementation of safe healthcare waste management practices through the prevention of hazardous healthcare waste generation. However, accumulation of pharmaceutical waste in hospitals is an indicator of the existence of the system of healthcare waste management (HCWM) but not properly implemented and not as well developed as it should be. All hospital personnel dealing with healthcare waste should be familiar with the main categories of healthcare waste as set out in either national or local regulations on waste classification and with safe procedures for HCWM. Special training activities concerning healthcare waste management including topics on pharmaceutical waste management is of upmost importance for the capacity improvement concerning safe HCWM. ${ }^{1}$

Legal framework for HCWM in most countries consists of a Law on Waste Management and some bylaws concerning safe healthcare waste management. ${ }^{2}$

In the Republic of Serbia, the key legal framework for healthcare waste management comprises of the Law on Waste Management and various Rulebooks, including a Rulebook on Healthcare Waste Management (hereinafter: the Rulebook). ${ }^{3}$

This Rulebook on healthcare waste management details the methods of managing hazardous healthcare waste, including proposed safe methods for pharmaceutical waste management.

According to the Serbian Rulebook, healthcare waste is waste generated in the course of providing healthcare services to humans and it comprises hazardous and non-hazardous waste categories defined and classified in the Serbian Waste Catalogue. ${ }^{4}$ Serbian Waste Catalogue is developed in line with the EU Waste Catalogue. ${ }^{5}$ According to the Rulebook on Healthcare Waste Management, there are two categories of healthcare waste in Serbia: 1) non-hazardous healthcare waste and 2) hazardous healthcare waste. The provisions for hazardous healthcare waste prescribe special handling of (1) path anatomical waste, (2) sharps, (3) pharmaceutical (4) cytotoxic and cytostatic waste (5) waste contaminated by blood and body fluids (6) infectious waste (7) other hazardous healthcare waste (chemical waste, waste with a high heavy metal content and waste pressurized containers). ${ }^{4,5}$
Pharmaceutical waste stream management is influencing the quality of HCWM in every healthcare facility, particularly in hospitals because of the quantity of waste generated. According to the Rulebook, this waste stream includes all remnants of medication, including their primary packaging, as well as all devices used for their administration, which a healthcare worker providing healthcare services to the population is in possession of, and which have become unusable due to expiration of their expiration date, non-compliance with the prescribed quality standards, contamination of their packaging, spills, medications that have been prepared and then not used, those returned by the end users, or those that cannot be used for any other reason. This type of waste can be: 1) potentially hazardous pharmaceutical waste, i.e. waste representing a risk in case of improper handling and requiring handling according to procedures prescribed for hazardous waste and 2) hazardous pharmaceutical waste, which is the waste originating from medicines and disinfectants comprising heavy metals, as well as medicines with undetermined contents, which requires special treatment methods.

Unused cytotoxic and cytostatic medications is considered as a hazardous healthcare waste and it's composed of medications and primary packaging and all devices used in preparation of such products for cancer chemotherapy. Cytotoxic and cytostatic medicines are toxic substances with carcinogenic, mutagenic and/or teratogenic effects. Cytotoxic drugs are most often used in specialized departments, such as oncology and radiotherapy units, whose main role is cancer treatment. ${ }^{6}$

As the guideline of WHO "Safe management of waste from healthcare activities" clearly states, pharmaceutical waste includes expired, unused, spilt and contaminated pharmaceutical products, prescribed and proprietary drugs, vaccines and sera that are no longer required, and, due to their chemical or biological nature, need to be disposed of carefully. ${ }^{2}$ The category also includes discarded items heavily contaminated during the handling of pharmaceuticals, such as bottles, vials and boxes containing pharmaceutical residues, gloves, masks and connecting tubing. Healthcare waste management in healthcare facilities in total pertains to a group of measures encompassing collection, segregation, packaging, labelling, storage, transport, treatment and safe disposal of healthcare waste.

One of the most important tasks for the staff of healthcare facilities that is appointed to be in charge for proper HCWM is prevention of generation of large quantities of hazardous healthcare waste including pharmaceutical waste and achievement of total healthcare waste minimization. 
However, procedures for proper labelling of segregated pharmaceutical waste are also their tasks and it's of great importance for safe pharmaceutical waste management in hospitals. In different counties there are different colour coding systems for labelling of pharmaceutical and cytostatic waste. In Serbia segregated pharmaceutical waste is packed in the red containers or red bags, while cytostatic waste is packed in purple containers or bags. Infectious waste is packed in yellow bags or containers; and other hazardous waste (chemical) - in red containers. In the most EU countries there is the same colour coding system since Serbian model for colour coding of healthcare waste streams is taken from the EU countries experience and practices. Treatment of pharmaceutical and cytotoxic waste goes on by using physical and chemical procedures, or by incineration in facilities licensed for hazardous waste treatment. ${ }^{6-8}$

After segregation and collection pharmaceutical and cytostatic and cytotoxic wastes are stored in hospitals prior to their export. Pharmaceutical waste containing psychoactive controlled substances and precursors is treated in line with the laws regulating the field of psychoactive controlled substances and precursors, law regulating medications and law regulating waste management. This waste stream is generated in minimal quantities.

Where the production of pharmaceutical waste is unavoidable, hospital policies are in place to ensure the safe segregation, handling and disposal of waste and that all persons handling any such waste shall exercise care to avoid injury or risk of harm to themselves or others, including general public. ${ }^{9-10}$

All hospital personnel dealing with healthcare waste should be trained for HCWM. After training, staffs become familiar with the main categories of healthcare waste and required procedures for their handling. As a minimum, managers responsible for healthcare waste system in hospital should conduct audit activities throughout the facility, to identify where these waste streams are produced, to obtain an initial estimate of the types and quantities of waste generated, and to assess how the waste is handled and disposed of. A rapid assessment, combining observations with interviews and survey questionnaires, provides sufficient data to identify problems and begin the process of addressing them. ${ }^{11-13}$ all hospital staff is committed to the protection of human health and the environment.

\section{METHODS}

The research was conducted as a cross-sectional study on the entire population of state owned hospitals at secondary and tertiary level of healthcare in the Republic of Serbia, in November 2014. Data were collected by filling in 30 a questions questionnaire that was specially designed for this research based on the UN-WHO guide for rapid healthcare waste management assessment (UN-WHO HCWM Rapid Assessment Tool). The questionnaire was pretested before the usage in this research. 25 administrative districts in Serbia have been included in the research located within 4 regions of Serbia (Belgrade, Vojvodina, Sumadija and Western Serbia, Southern and Eastern Serbia). The research sample was composed of 60 hospitals that have been chosen in total, from each healthcare district at random. The only criterion was that the healthcare facilities be a state -owned hospitals on the territory of the Republic of Serbia in the 4 regions mentioned above. The sample size was defined based on pilot studies conducted in Serbia during the implementation of an EU funded project concerning the improvement of Healthcare Waste Management (2007-2009). Based on the conducted pilot studies expected correlation coefficient of the healthcare waste and the number of beds in hospitals is 0.35 . For the level of correlation of 0.35 and the power of the study $1-=0.8$, and the level of $=0.05$, a sufficient number of observation units is 60 .

The direct participants in the research were representatives of the hospitals, i.e. persons appointed as responsible for HCWM (managers or technicians for HCWM). The questions from the questionnaire were related to the number of healthcare services provided by the hospitals, numbers of hospital beds as well as the bed occupancy rate at an annual level, training activities and education of the hospital personnel for HCWM.

The questions were related also to the practice of hospital staff concerning pharmaceutical waste and its disposal, including quantities of segregated pharmaceutical waste annually.

All statistical analyses were performed using IBM SPSS Statistics for Windows Software Version 20.0. Results were presented as mean and standard deviation (mean \pm standard deviation). Along with a descriptive analysis, Mann-Whitney U-test and Spearman's correlation were used as methods of checking for correlations in line with pertinent questions. P-values under 0.05 were considered statistically significant.

The Ethics Committee of the Institute of Public Health of Serbia has approved this research (No. 1554/1).

\section{RESULTS}

60 hospitals, located in 4 regions of the Republic of Serbia (Belgrade, Vojvodina, Šumadija and Western Serbia and 
Southern and Eastern Serbia) at secondary and tertiary levels of healthcare were included in the research. Persons responsible for HCWM in hospitals filled in the questionnaire. For the purpose of the research each hospital was represented by one filled out questionnaire. Of the 60 analyzed questionnaires, 47 were from secondary-level hospitals, while 13 were tertiary healthcare institutions.

Data analysis has shown that Clinical centres generated the largest quantity of pharmaceutical and cytostatic waste in all regions. Belgrade was the region with the largest amounts of pharmaceutical and cytostatic waste generated per year (generated by the Clinical Centre).

Special hospitals in Vojvodina and Belgrade regions did not produce cytostatic waste at all.

The smallest amount of pharmaceutical waste $(44.4 \mathrm{~kg} /$ year) was generated in the Special Hospital in Vojvodina. More cytostatic waste was generated per year than pharmaceutical waste (Graphic 1). The largest amount of cytostatic waste was generated in Belgrade, in the Clinical Centre, while Clinic in Belgrade produced the smallest quantity of this waste stream ( $5 \mathrm{~kg} /$ year).

Analysis showed a statistically significant difference between healthcare levels, when it comes to medical waste generation in total $(U=198, p=0.006)$, and pharmaceutical waste generation $(\mathrm{U}=221, \mathrm{p}=0.018)$ in a healthcare setting. Tertiary healthcare level hospitals produced statistically significantly larger quantities of healthcare waste than secondary level hospitals.

Distribution of hospitals by type of institution (general hospital, special hospital, institute, clinic, clinical hospital centre, clinical centre), regions (4 regions) and generation of pharmaceutical and cytostatic waste per year is presented in Table 1.

Further statistical analysis of the data gathered showed no statistically significant difference between levels of healthcare with regards to cytostatic waste generation $(\mathrm{U}=287, \mathrm{p}=0.195)$. Statistic testing revealed a high statistical significance between levels of healthcare

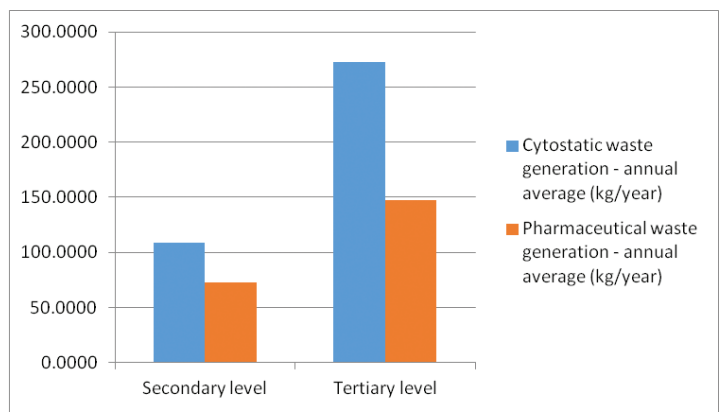

Graphic 1: The amount of the pharmaceutical and cytostatic waste generated in hospitals per year and generation of pharmaceutical waste $(\mathrm{U}=221$, $\mathrm{p}=0.0,018)($ Table 2).

In addition, statistical testing revealed a high statistical significance between the type of hospital and generation of pharmaceutical $(\mathrm{x} 2=14.3, \mathrm{df}=5, \mathrm{p}=0.14)$ and cytostatic waste $(\mathrm{x} 2=17.4, \mathrm{df}=5, \mathrm{p}=0.004)$ (Table 3).

As for the training of the staff for healthcare waste management (HCWM), it was determined that in total, in 2014, 86 medical and non-medical staff were trained through external training (Table 4).

The largest number of staff trained for HCWM was registered at tertiary level of healthcare institutions (94\% of tertiary level institutions). Still, one in five hospitals had no staff trained for HCWM. Training was conducted using two training curricula, one for HCWM Technicians and the other for HCWM Managers.

Spearman's rho statistical test showed a significant and direct correlation between the numbers of beds, number of hospital days and the number of personnel trained as managers and technicians for HCWM, including modules for pharmaceutical waste management (Table 5).

Based on the calculated value of the Spearman's rank correlation coefficients research shows that the amount of pharmaceutical and cytostatic waste generated in hospitals correlated significantly and directly to the number of services provided by the hospital, number of beds and number of staff trained for HCWM. This means that healthcare institutions that have a larger number of bed-days and more staff trained for HCWM generate a larger amount of both waste streams, while simultaneously segregating larger quantities of these two waste streams.

\section{DISCUSSION}

Promotion of proper handling and disposal of pharmaceutical waste is an important activity for each hospital. Segregation of pharmaceutical and cytostatic waste immediately after administration of medications including anti-cancer therapy is a very important daily practice in hospitals. ${ }^{1,2}$ Nowadays, many developing and undeveloped countries increased healthcare waste segregation in order to implement safe practices for disposal and management of hazardous waste streams, which usually comprises infectious, pathological and pharmaceutical waste. Cytostatic and cytotoxic waste is more often segregated at the point of generation, in special departments for cancer treatment. ${ }^{2}$ as the research in Serbia shows; this waste stream combines two hazards in a single waste type, infectiousness and toxicity. These examples exist in many developed countries as well. In the United States of America when hazardous drug 


\section{Table 1: Distribution of hospitals per type of institution, region and pharmaceutical and cytostatic waste generation}

\begin{tabular}{|c|c|c|c|}
\hline \multirow{2}{*}{ Region } & Type of hospital & $\begin{array}{c}\text { Average generation of } \\
\text { cytostatic waste kg/ } \\
\text { year }\end{array}$ & $\begin{array}{c}\text { Average generation of } \\
\text { pharmaceutical waste } \\
\text { kg/year }\end{array}$ \\
\hline \multirow{3}{*}{ Vojvodina } & General hospital & 171.67 & 86.56 \\
\cline { 2 - 4 } & Special hospital & 0.00 & 44.45 \\
\cline { 2 - 4 } & Institute & 190.00 & 62.67 \\
\hline \multirow{3}{*}{ Belgrade } & Clinical Centre & 350.00 & 280.00 \\
\cline { 2 - 4 } & Special hospital & 0.00 & 27.00 \\
\cline { 2 - 4 } & Institute & 170.00 & 98.50 \\
\cline { 2 - 4 } & Clinic & 5.00 & 62.50 \\
\cline { 2 - 4 } & Clinical Centre & 177.50 & 92.75 \\
\hline \multirow{3}{*}{ Šumadija and Western Serbia } & General Hospital & 1.250 .00 & 650.00 \\
\cline { 2 - 4 } & Clinical Centre & 133.00 & 77.93 \\
\hline \multirow{3}{*}{ Southern and Eastern Serbia } & General Hospital & 380.00 & 250.00 \\
\cline { 2 - 4 } & Special hospital & 69.06 & 62.88 \\
\cline { 2 - 4 } & Clinical Centre & 50.00 & 85.00 \\
\hline
\end{tabular}

T able 2: Correlation between healthcare level and pharmaceutical and cytostatic waste generation

\begin{tabular}{|c|c|c|c|c|c|c|c|}
\hline Mann-Whitney Test & & & & & & & \\
\hline Variables & Referrals & $\mathbf{N}$ & $\begin{array}{l}\text { Mean } \\
\text { Rank }\end{array}$ & Median & Mann-Whitney U & $\mathbf{z}$ & $\begin{array}{l}\text { Asymp. Sig. } \\
\text { (2-tailed) }\end{array}$ \\
\hline \multirow{3}{*}{$\begin{array}{l}\text { Pharmaceutical waste generation } \\
\text { kg/year }\end{array}$} & Secondary level & 43 & 27.14 & 65.00 & \multirow{3}{*}{221.00} & \multirow{3}{*}{-2.372} & \multirow{3}{*}{0.018} \\
\hline & Tertiary level & 17 & 39.00 & 89.00 & & & \\
\hline & Total & 60 & & & & & \\
\hline \multirow{3}{*}{$\begin{array}{c}\text { Cytostatic waste generation } \\
\text { kg/year }\end{array}$} & Secondary level & 43 & 28.67 & 85.00 & \multirow{3}{*}{287.00} & \multirow{3}{*}{-1.296} & \multirow{3}{*}{0.195} \\
\hline & Tertiary level & 17 & 35.12 & 150.00 & & & \\
\hline & Total & 60 & & & & & \\
\hline
\end{tabular}

Table 3: Correlation of hospital type and quantity of pharmaceutical and cytostatic waste generated per year

\begin{tabular}{|c|c|c|c|c|c|c|c|}
\hline \multicolumn{8}{|c|}{ Kruskal-Wallis Test } \\
\hline \multicolumn{2}{|c|}{ Type of hospital } & $\mathbf{N}$ & Mean Rank & Median & Chi-Square & df & Asymp. Sig. \\
\hline \multirow{7}{*}{$\begin{array}{l}\text { Cytostatic waste } \\
\text { generation kg/year }\end{array}$} & General hospital & 40 & 29.96 & 105.00 & \multirow{7}{*}{17.454} & \multirow{7}{*}{5} & \multirow{7}{*}{.004} \\
\hline & Special hospital & 3 & 11.50 & 0.00 & & & \\
\hline & Institute & 7 & 26.43 & 10.00 & & & \\
\hline & Clinic & 2 & 10.75 & 5.00 & & & \\
\hline & Clinical Hospital Centre & 4 & 40.25 & 165.00 & & & \\
\hline & Clinical centre & 4 & 57.38 & 530.00 & & & \\
\hline & Total & 60 & & & & & \\
\hline \multirow{7}{*}{$\begin{array}{c}\text { Pharmaceutical waste } \\
\text { generation kg/year }\end{array}$} & General hospital & 40 & 27.85 & 70.00 & \multirow{7}{*}{14.307} & \multirow{7}{*}{5} & \multirow{7}{*}{.014} \\
\hline & Special hospital & 3 & 17.67 & 44.45 & & & \\
\hline & Institute & 7 & 32.07 & 70.00 & & & \\
\hline & Clinic & 2 & 23.25 & 62.50 & & & \\
\hline & Clinical Hospital Centre & 4 & 39.50 & 97.00 & & & \\
\hline & Clinical centre & 4 & 58.50 & 265.00 & & & \\
\hline & Total & 60 & & & & & \\
\hline
\end{tabular}

\footnotetext{
**. Correlation is significant at the 0.05 level.
} 


\begin{tabular}{|c|c|c|c|c|}
\hline Table 4: Staff trained for HCWM - Technicians and Managers \\
\hline & $\begin{array}{c}\text { Secondary } \\
\text { level }\end{array}$ & Tertiary level \\
\hline Number of trained HCW Managers & 43 & 27 & 17 & 16 \\
\hline Number of trained HCW Technicians & 43 & 28 & 17 & 15 \\
\hline
\end{tabular}

\begin{tabular}{|c|c|c|c|c|}
\hline \multicolumn{5}{|c|}{ Correlations } \\
\hline & & & $\begin{array}{l}\text { Pharmaceutical } \\
\text { waste generation } \\
\text { kg/year }\end{array}$ & $\begin{array}{c}\text { Cytostatic waste } \\
\text { generation kg/ } \\
\text { year }\end{array}$ \\
\hline \multirow{12}{*}{ Spearman's rho } & \multirow{3}{*}{ Number of services } & Correlation Coefficient & $.719^{\star *}$ & $.625^{\star *}$ \\
\hline & & Sig. (2-tailed) & .000 & .000 \\
\hline & & $\mathrm{N}$ & 60 & 60 \\
\hline & \multirow{3}{*}{ Number of beds } & Correlation Coefficient & $.908^{* *}$ & $.757^{\star *}$ \\
\hline & & Sig. (2-tailed) & .000 & .000 \\
\hline & & $\mathrm{N}$ & 60 & 60 \\
\hline & \multirow{3}{*}{$\begin{array}{c}\text { Number of trained } \mathrm{HCW} \\
\text { Managers }\end{array}$} & Correlation Coefficient & $.645^{\star *}$ & $.530^{* *}$ \\
\hline & & Sig. (2-tailed) & .000 & .000 \\
\hline & & $\mathrm{N}$ & 60 & 60 \\
\hline & \multirow{3}{*}{$\begin{array}{c}\text { Number of trained HCW } \\
\text { Technicians }\end{array}$} & Correlation Coefficient & $.276^{*}$ & $.259^{*}$ \\
\hline & & Sig. (2-tailed) & .033 & .046 \\
\hline & & $\mathrm{N}$ & 60 & 60 \\
\hline
\end{tabular}

waste is infectious, a double hazard exists. Some states may require a separate waste stream for infectious hazardous pharmaceutical waste. With the extra time and caution required, this may be one of the most expensive waste streams to manage. This waste must be separated for proper handling by a special permitted incinerator. ${ }^{10}$

Primary waste legislation is the key instrument for the improvement of pharmaceutical waste management in many countries. Since pharmaceutical waste includes expired, unused, split and contaminated pharmaceuticals, drugs, vaccines, and sera that are no longer required, it needs to be disposed of appropriately. This category also includes discarded items used in the handling of pharmaceuticals, such as bottles or boxes with residues, gloves, masks, connecting tubing, and drug vials. Recommendations and guidelines from $\mathrm{WHO}$ and UN are of upmost importance for the establishment of proper healthcare waste management in healthcare facilities, including proper waste management plan and pharmaceutical waste management. ${ }^{9}$

Research shows that hospitals in Serbia generate significant quantities of pharmaceutical waste. Research also underlined that there is a direct correlation between the number of hospital days, number of outpatient services and quantity of segregated cytostatic and pharmaceutical waste.

For decades in Serbia, pharmacies were recognised as the main generators of pharmaceutical waste. In the last 20 years, new practices of healthcare professionals concerning HCWM brought about changes in pharmaceutical waste management in the world. Since 2009, these practices came to Serbia in a more organised manner. As research shows, hospitals in Serbia became significant generators of pharmaceutical and cytostatic waste as well.

Training for proper and safe management of healthcare waste, including pharmaceutical and cytostatic waste in hospitals is of great importance for dealing properly with these types of hazardous healthcare waste. This training has to be in accordance with the legal framework and good practice guidelines on HCWM, abiding the rules set up by WHO's recommendations and implemented in a number of countries, India included. ${ }^{18-19}$

Training for Healthcare Waste Management in Serbia takes place as external training, as continual medical 
education, organized by the Institute of Public Health of Serbia and as an internal training program organized by hospitals. Results from the research show that there is a direct correlation between the number of trained personnel and pharmaceutical waste management, which is currently measured by the quantity of generated waste.

Knowing the types and quantities of waste produced in a healthcare facility, including hospitals, is an important first step in safe waste disposal. Waste-generation data are used in estimating the needs for the proper waste management including capacities for containers, storage areas, and transportation and treatment technologies. Waste generation data can be used to establish baseline data on waste generation rates in different medical fields and for procurement specifications, planning, budgeting, calculating revenues from recycling, optimization of waste-management systems, and environmental impact assessments. $^{2}$ these measures are partially present in Serbia, but still it is the beginning of proper pharmaceutical waste management in hospitals which requires further improvement.

\section{CONCLUSION}

- Proper management and disposal of pharmaceutical waste that meet the definition of hazardous waste are not non-compulsory in the Republic of Serbia - since 2009 they have been required by law. Even so, the practice of all legal requirements concerning pharmaceutical waste management is not fully implemented in all hospitals. Pharmaceutical waste management practices in hospitals are incomplete, when it comes to collection, proper segregation, storage and disposal of this waste stream. Large quantities of pharmaceutical waste are still being generated, which is an indicator of the average quality of HCWM in hospitals.

- Hospitals have different practices concerning pharmaceutical and cytostatic waste management due to the different level of education of the staff on this issue. There is a need for strengthening the education of hospital staff concerning proper pharmaceutical waste management.

- A larger quantity of pharmaceutical waste is produced in tertiary-level hospitals, since the number of hospital days and the numbers of outpatient services are bigger in these hospitals. There is a need for further improvement of this practice in said hospitals and for the introduction of specific operational procedures (SOPs) so that this waste stream management could be a useful strategy for improvement.
- Hospitals in Serbia face a challenge on this particular front, when met with the matter of applying the practise of sorting out and dealing with pharmaceutical waste encouraged by law; whether to upon the collection of waste hire an operator to pick up with the managing process and risk running out of assets to compensate said operator with or to store collected waste within the facility for longer than 12 months and avoid mentioned risk, but become viable for legal prosecution by inspection officials, because this course of action goes against the law outline for holding onto medical waste.

- Pharmaceutical waste collected in hospitals is exported abroad through licensed private operators. Financing of pharmaceutical and cytostatic waste export and proper disposal is not fully regulated in practice, since there are often uncertainties relating to regular payment of these costs in hospitals. In order to avoid an impasse in the export of said waste, it is crucial to have access to a stable form of financing, as well as to lay out the costs of this necessity in the facility's yearly business plan.

- Further improvement of pharmaceutical waste management is to be achieved through more frequent training opportunities and, consequently, a larger number of specialists trained in the field of pharmaceutical waste management. The Public Health Institute of Serbia "Dr Milan Jovanovic Batut" has to propose a training plan for all hospitals based on training needs.

- Relicensing HCW managers and technicians, including additional modules on pharmaceutical and cytostatic waste management should be made mandatory in Serbia and published in the new regulations, aimed at achieving further improvement of healthcare waste management.

- The annual revision of dealing with pharmaceutical waste within a facility might be a great way to improve HCWM in general.

\section{ACKNOWLEDGMENT}

The research was conducted by using WHO questioner. Usage of questioner was for the first time in Serbia during EU funded projects of Ministry of Health and Ministry of Environmental Protection implemented in Serbia in 2008 ("Technical Assistance for Healthcare Waste Management" - “04SER01/08/001, and 2011 "Technical Assistance for Healthcare Waste Treatment in Serbia" (8SER/31/12/00)). The authors would like to thank to Mr Jan Gerd Kuhuling and Mr Jan Gerrit Tesink for their support and advice for the experience 
they gained about proper usage of said questioner, used in this research.

\section{CONFLICT OF INTERESTS}

There is no conflict of interests concerning data presentation and analysis by the authors.

\section{ABBREVIATION USED}

WHO: World Health Organization; HCWM: Health Care Waste Management; EU: European Union; UN: United Nations; IBM SPSS: International Business Machines Statistical Package for the Social Science; SOPs: Standard Operational Procedures.

\section{REFERENCES}

1. Healthcare waste. Fact Sheet No 253, WHO, 2015.

2. Safe management of wastes from healthcare activities. Second edition, Yves Chartier, Jorge Emmanuel, Ute Pieper et al., WHO, Malta, ISBN 978924 154856 4, 2014.

3. Law on waste management, Official Gazette 36/2009, 88/2010, 16/2016. Government of the Republic of Serbia, Belgrade, 2009.

4. Rulebook on healthcare waste management, Official Gazette 78/2010, Government of the Republic of Serbia, Belgrade, 2010.

5. European waste catalogue. European Union, Commission Decision 2000/532/EC, 2000. https://www.gov.uk/ how-to-classify-different-types-ofwaste/healthcare-and-related-wastes

6. ASHP technical assistance bulletin on handling cytotoxic and hazardous drugs, American Journal of Hospital Pharmacy. American Society of Hospital Pharmacists, 1990;47(5):1033-49.

7. Goodin S et al. Safe handling of oral chemotherapeutic agents in clinical practice: recommendations from an international pharmacy panel. Journal of Oncology Practice, 2011. http://dx.doi.org/10.1200/JOP.2010.000068; PMid:21532802 PMCid:PMC3014516
8. Preventing occupational exposures to antineoplastic and other hazardous drugs in healthcare settings. National Institute for Occupational Safety and Health, US DHHS PHS, NIH. 2004. Pub No. 92-2621. (www.cdc.gov/niosh/ docs/2004-165/pdfs/2004-165.pdf),

9. White RJ, Belmont AM, Metcalfe DC. Pharmaceutical Compounds in Wastewater: Wetland Treatment as a Potential Solution. The Scientific World Journal. 2006 http://dx.doi.org/10.1100/tsw.2006.287 ; PMid:17195871

10. Guidelines for the safe disposal of expired drugs. Amman, Jordan, WHO CEHA, 2006, http://www.emro.who.int/images/stories/pakistan/documents/ pak_documents/Guidelines_for_Expired_Medicines.pdf).

11. Managing pharmaceutical waste: a 10-step blueprint for health care facilities in the United States. Hospitals for a Healthy Environment. www. premierinc.com/safety/topics/pharma-waste/downloads/h2e-pharmablueprint-04-15-06.pdf (accessed 2007 July 14).

12. Starting health care waste management in medical institutions: a practical approach, WHO EURO (World Health Organization Europe Regional Office) Copenhagen, World Health Organization Europe Regional Office.2000.

13. Emmanuel J. Survey of health care waste characteristics and generation data from different countries. New York, United Nations Development Programme Global Environment Facility Global Demonstration Project on Health Care Waste, 2007.

14. Narendra M, Kousar H, Puttaiah ET, Thirumala S. Assessment of Biomedical waste of various hospitals in Mysore City Karnataka, India. International Journal of Current Microbiology and Applied Sciences. 2013;2(3):1-5.

15. Singh A, Singh J, Singh AP, Singh R. Biomedical waste management and their possible health risks with controlling measures in Bareilly city, UP, India. Octa Journal of Environmental Research. 2014; 2(4):296-302.

16. Arnold R. Optimization of Health Hazards caused by Bio-Medical Wastes from Health care Units in REWA, (Madhya Pradesh). World Journal of Pharmaceutical Research. 2015; 4(12):892-901.

17. Jaiswal S, Singh AK, Chowdhury K, Garg R. Biomedical Waste Management in a Charitable Hospital: A Case Study of Jingal Institute of Medical Science, Hisar District, India. Environment \& We An International Journal of Science \& Technology. 2010;5:115-122.

18. Patil GV, Pokhrel K. Biomedical solid waste management in an Indian hospital: a case study. Waste Management. 2005;25(6):592-9. http://dx.doi. org/10.1016/j.wasman.2004.07.011

19. Chaurasia S, Singh R, Gupta AD, Kumar S. Overview on Biomedical waste of District Hispital Satna (MP), India. Current Science Journal. 2014;10:49-53.

\section{SUMMARY}

- Nowadays, many developing and underdeveloped countries increase the quality of healthcare waste segregation in the hopes of implementing safe practices for the disposal and management of hazardous waste streams, usually comprised of infectious, pathological and pharmaceutical waste. The practice of all legal requirements concerning pharmaceutical waste management is not fully implemented in all hospitals in Serbia. Healthcare facilities improve the manner of dealing with hazadrodus healthcare waste, pharmaceutical waste included.

- The existence of adequate legal framework in the area of proper pharmaceutical waste management plays a key role in ameliorating the practice of handling hazardous waste in healthcare facilities.

\section{About Authors}

Verica Jovanović, MD: Specialist of public health, MSc, Institute of Public Health of Serbia "Dr Milan Jovanovic Batut", Belgrade, Serbia.

Jelena Manojlovic: Pharmacist, University of Belgrade Faculty of Pharmacy, Belgrade, Serbia.

Dragomir Jovanović, MD: Specialist of Gynaecology, Clinic for Gynecology and Obstetrics, GAK "Narodni front", Belgrade, Serbia.

Branislava Matic, MD: MSc, Specialist of Hygiene, Clinic for Gynecology and Obstetrics, GAK "Narodni front", Belgrade, Serbia.

Nela Đonović, MD: Specialist of Hygiene, Professor, University of Kragujevac, Medical Faculty, Kragujevac, Serbia. 